\title{
Use of mood stabilizer drugs in the treatment of major depressive dissorder in an outpatient mental health center
}

\author{
Carolina Garnier ${ }^{*}$, Juan Castaño, Patricia Alvaro, Rosa Sanchis, David Corcoles, Francisco Portillo, Belen Diaz, \\ Luis Miguel Martin, Antoni Bulbena
}

From $1^{\text {st }}$ International Congress on Neurobiology and Clinical Psychopharmacology and European Psychiatric Association Conference on Treatment Guidance

Thessaloniki, Greece. 19-22 November 2009

\section{Background}

Major depressive disorder (MDD) is a common and disabling psychiatric condition. Antidepressants are currently the mainstay of treatment for depression; however, almost two thirds of patients will fail to achieve remission with initial treatment, as a result, a range of augmentation and combination strategies have been used [1].

\section{Materials and methods}

Major depressive disorder (MDD) is a common and disabling psychiatric condition. Antidepressants are currently the mainstay of treatment for depression; however, almost two thirds of patients will fail to achieve remission with initial treatment, as a result, a range of augmentation and combination strategies have been used [1].

\section{Results}

Mood stabilizers are used in $14 \%$ of the sample with a predominancy in the female gender $(85.7 \%)$, a global average age $50.6 \pm 12.2$ years. Regarding personal psychiatric background, there's an absence of these in the first place (64.3\%), followed by the presence of previous depressive episodes (21.4\%) and dysthymic disorder (7.1\%). In none of these cases there was toxic abuse. There is a predominancy in the absence of previous psychiatric hospitalisations (64.3\%).

The frequencies of use of mood stabilizers was: topiramate in the first place $(50 \%)$ followed by lithium, carbamazepine and pregabaline (14.28\% each of them), in the last place lamotrigine $(7.1 \%)$. The average dose was $900 \mathrm{mg} / \mathrm{d}$ for carbamazepine, $600 \mathrm{mg} / \mathrm{d}$ for lithium, $300 \mathrm{mg} / \mathrm{d}$ for pregabaline, $128.5 \mathrm{mg} / \mathrm{d}$ for topiramate and $100 \mathrm{mg} / \mathrm{d}$ for lamotrigine.

\section{Conclusions}

In our sample the frequency of use of lithium is similar to the registered for the several antiepiletics (lithium, carbamazepine and pregabaline: $14.28 \%$ each one). However, lithium addition is recommended as a first choice for depressed patients who do not respond to therapy with conventional antidepressants [2].

Published: 22 April 2010

\section{References}

1. Craig Nelson J, Pikalov A, Berman R: "Augmentation treatment in major depressive disorder: focus on aripiprazole". Neuropsychiatri Dis Treat San Francisco 2008, 4(5):937-948.

2. Baver M, Döpfmer S: Lithium augmentation in treatment-resistant depresión: metaanalysis of placebo-controlled studies. J Clin Psychopharmacol. 1(5):427-434.

doi:10.1186/1744-859X-9-S1-S168

Cite this article as: Garnier et al: Use of mood stabilizer drugs in the treatment of major depressive dissorder in an outpatient mental health center. Annals of General Psychiatry 2010 9(Suppl 1):S168.

Department of Psychiatry, Hospital del Mar, IAPS, Barcelona, Spain 